\title{
LAS VICISITUDES DE LA ESPERANZA LIBERAL: DE LA UTOPÍA MINARQUISTA A LA DISTOPÍA ANARCOCAPITALISTA*
}

\author{
Felipe Schwember Augier
}

Universidad Adolfo lbáñez

\begin{abstract}
RESUMEN: El presente trabajo repasa diferentes versiones de las utopías libertarias y anarcocapitalistas que han germinado al alero del concepto de propiedad sobre sí mismo, característico del liberalismo libertario. Al hilo de dicho repaso, se pretende demostrar cómo, a partir de la identificación de la voluntariedad con la no coacción, el abandono de la estipulación de Locke o, en fin, la reducción de las relaciones de justicia a la justicia correctiva, las utopías minarquistas y anarcocapitalistas terminan en distopías. Esos resultados distópicos permiten mostrar, además, cómo y cuánto se aleja el anarcocapitalismo del liberalismo, en cualquiera de sus versiones. Ese alejamiento, se sostiene, culmina en una teoría política no liberal, sui generis, que cabría denominar "neofeudalismo".

Palabras Clave: liberalismo libertario, utopías, Nozick, Kukathas, distopías, anarcocapitalismo, neofeudalismo.

RECIBIDO: marzo 2019; ACEPTADO: junio 2019.
\end{abstract}

Felipe Schwember Augier. Licenciado en derecho y en filosofía por la Universidad Católica de Chile. Doctor en filosofía por la Universidad de Navarra. Profesor del Centro de Investigación en Teoría Social y Política de la Escuela de Gobierno, Universidad Adolfo Ibáñez. Email: felipe.schwember@uai.cl.

* Una versión preliminar de este artículo apareció en inglés en Schwember (2019). El autor agradece los comentarios y sugerencias de los evaluadores de Estudios Públicos, que contribuyeron a mejorar este trabajo, así como la lectura, las conversaciones y sugerencias de Daniel Loewe y Valentina Verbal. 


\section{THE VICISSITUDES OF LIBERTARIAN HOPE: FROM THE MINARCHIST UTOPIA TO THE ANARCHO-CAPITALIST DYSTOPIA}

ABSTRACT: The present work reviews different versions of the libertarian and anarcho-capitalist utopias that have developed from the concept of self-ownership, keystone of libertarianism. The purpose of this review is to demonstrate how, from the identification of voluntariness with non-coercion, the abandonment of Locke's proviso or, in short, the reduction of relations of justice to corrective justice, the minarchist and anarcho-capitalist utopias end in dystopias. These dystopian results also show in what way and how far anarcho-capitalism moves away from liberalism, in any of its versions. That distancing, it will be argued, culminates in a non-liberal political theory, sui generis, which could be called "neofeudalism".

Keywords: Libertarianism, utopias, Nozick, Kukathas, dystopias, anarchocapitalism, neofeudalism.

RECEIVED: March 2019; ACCEPTED: June 2019.

\section{INTRODUCCIÓN}

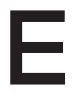

n buena medida, el liberalismo del siglo XX se comprendió a sí mismo como la némesis de las grandes utopías. Algunos de sus más importantes teóricos realizaron enérgicas condenas de las utopías y sus tentaciones. Popper y Hayek pueden, en este sentido, ser considerados dos autores paradigmáticos: ambos ofrecen sesudos razonamientos para enrielar a los lectores desprevenidos y conjurar cualquier veleidad utópica. La utopía, advierten ambos, es un error intelectual o moral; un extravío tan peligroso como seductor, que nos persuade no sólo de la posibilidad de alcanzar un paraíso terrenal, sino que también de que ningún precio por hacerlo es demasiado alto. ${ }^{1}$

Popper enfatiza este peligro mediante la ecuación utopía-fanatismo-violencia: quien se convence de una utopía se ha convencido, básicamente, de los fines últimos de la vida política y, por lo mismo, de la inutilidad o impertinencia de cualquier discusión crítica acerca de esos fines. La imposibilidad de entablar una discusión crítica (y no meramente estratégica) acerca de los fines últimos destruye el ethos

\footnotetext{
${ }^{1}$ Ver Popper (2017, 173-184) y Hayek (2006).
} 
democrático y abre las puertas al fanatismo. La utopía desemboca, invariablemente, en la violencia (Popper 1991, 425-435).

Hayek, por su parte, subraya la conexión entre utopía y totalitarismo, advirtiendo acerca de la imposibilidad de ciertas formas de planificación particularmente ambiciosas, de los riesgos que esas formas de planificación entrañan para la libertad individual y, por último, de la inconsistencia que existe entre esas formas de planificación y los fines que con ellas se quiere alcanzar (Hayek 2006). Por eso, y dado que el hecho de carecer de una utopía propia constituye una gran desventaja a la hora de reclutar prosélitos, los liberales deberían saber construir su propia utopía, evitando, sin embargo, al mismo tiempo, los peligros que ello entraña (Hayek 2012, 274; Hayek 2006, 89-90).

Entonces, si atendemos a Popper y Hayek, el liberalismo clásico del siglo XX es una doctrina política antiutópica, por dos razones básicamente. Primero, porque no sólo renuncia, sino que además se opone frontalmente a la idea de que es posible identificar, de modo inequívoco, fines últimos de la organización política a partir de los cuales levantar una "sociedad ideal", y segundo, porque la suya es fundamentalmente una estrategia de contención: su esfuerzo incesante por conjurar las pesadillas políticas se traduce no sólo en la renuncia a promover un fin último de la sociedad política, sino que también en el intento, más deslucido y modesto, de atajar las políticas impracticables. Popper ofrece un ejemplo particularmente claro de estos dos aspectos antiutópicos del liberalismo, cuando afirma que la finalidad de la política es combatir los males "más graves y serios de la sociedad" y no "encaminar todos sus esfuerzos hacia la consecución del bien final" $(2017,174)$.

Por consiguiente, si hubiese que definir la posición del liberalismo respecto de la utopía a partir de las posiciones de Popper y de Hayek, habría que decir que el liberalismo tiene una posición ambivalente, pues oscila entre la utopofobia ${ }^{2}$ y la añoranza de la utopía (utopía de la utopía).

Sin embargo, no mucho después de estas enérgicas denuncias, la utopía parece haber obtenido carta de ciudadanía en el pensamiento liberal. Primero en el liberalismo libertario, a través de la "metautopía" que Robert Nozick defiende en Anarchy, State, and Utopia (en adelante

\footnotetext{
${ }^{2}$ La expresión es de Estlund (2014).
} 
$A S U$ ), y luego en el liberalismo igualitario, a través de la "utopía realista" que John Rawls describe en su obra The Law of Peoples. Ambos casos han dado lugar a una serie de reflexiones y proyectos melioristas: utopías de la justicia global, utopías de fronteras abiertas, utopías multiculturalistas, utopías de la tolerancia o de la autonomía, etcétera.

En este trabajo me detendré en una serie de utopías - es decir, descripciones de ciudades u órdenes políticos ideales - que han germinado al alero de la metautopía de Nozick. Me refiero a las utopías libertarias y anarcocapitalistas, a las que denominaré genéricamente "utopías del derecho privado", en razón de las premisas que comparten acerca de las reglas de justicia: la propiedad de cada uno sobre sí mismo (selfownership), la libertad contractual, el contrato como única fuente de obligaciones políticas y el principio de no agresión.

El objetivo de este análisis es, por una parte, repasar la evolución de tales utopías, desde su formulación original en Nozick hasta sus versiones más recientes en la filosofía de algunos autores anarcocapitalistas. Por otra, y al hilo de este repaso, se intenta rastrear la causa de la mutación de las utopías del derecho privado en distopías capitalistas. Si es cierto que en toda utopía anida una distopía,${ }^{3}$ el propósito general de este trabajo es, entonces, buscar el lugar en que se aloja la semilla de la que brotan las distopías contemporáneas - especialmente anarcocapitalistas - del derecho privado.

Al respecto, sostendré que la deriva distópica de las utopías del derecho privado se explica, por una parte, por la identificación de "no coacción" con "voluntariedad" y, por otra, por la adopción de la propiedad como modelo de los derechos subjetivos en general. La noción que de la voluntariedad y de los derechos subjetivos tienen los libertarios conduce por sí misma a ciertos resultados distópicos (como, por ejemplo, la admisión del chantaje como práctica legal) o desactiva principios y prohibiciones, frecuentes en los ordenamientos jurídicos, que precisamente evitan dichos resultados distópicos (por ejemplo, para evitar que las conductas discriminatorias puedan ser consideradas un derecho, etcétera). En este sentido, argumentaré que el proton pseudos de las utopías del derecho privado se encuentra en la tendencia de sus autores a prescindir todo lo posible de principios universales e intersubjetivos

${ }^{3} \mathrm{Al}$ respecto, Schwember y Urabayen (2018). 
en la configuración del sistema jurídico. Esta tendencia propicia la fragmentación del ordenamiento político y jurídico en múltiples estatutos e "islas normativas" (neofeudalismo), así como en la desaparición del concepto de ciudadanía de la filosofía política.

La finalidad de este artículo es no sólo académica, sino también, hasta cierto punto, práctica. Me gustaría creer que con él puedo contribuir a que el lector conozca algunas de las ideas de fondo que modelan o informan el debate público. Aunque la mayor parte de las veces la conexión entre una doctrina y la política práctica sea más bien lejana, y aunque rara vez un político o un partido adopten una filosofía de modo, digamos, cabal, sigue siendo cierto que las teorías políticas y, sobre todo, las utopías políticas, informan la política práctica. La socorrida frase de Keynes acerca de la influencia de los economistas muertos sobre los políticos es cierta también, y tal vez con mayor razón, por lo que toca a la influencia que los filósofos ejercen sobre los políticos.

Por eso, no debería causar extrañeza que el aserto de Keynes (o, mejor dicho, la variante de él que hemos adoptado) sea igualmente válido para las teorías políticas-utopías que aquí revisaré: al lector perspicaz seguramente no le será difícil rastrear hasta ellas algunos de los tópoi argumentativos del discurso político contemporáneo de la así llamada "nueva derecha" o derecha "Alt-Right", que ha cobrado una súbita e insospechada importancia con la llegada al poder de Donald Trump en los Estados Unidos o el triunfo del "Brexit" en el Reino Unido.

En buena medida, esa derecha es una reacción a las "políticas de identidad", esto es, a las políticas que esgrimen las peculiaridades raciales, nacionales, religiosas, sexuales, etcétera, como locus de alguna pretensión o reivindicación política. La derecha "Alt-Right" ha reaccionado vigorosamente a esas políticas y ha sabido servirse de ellas para oponer su propia política identitaria, de carácter racista, nacionalista, cristiana, heteronormativa, etcétera (Fukuyama 2018).

Aunque esa nueva derecha no está inspirada única y exclusivamente en los movimientos libertarios o anarcocapitalistas, ni mucho menos, sí es cierto que ha recibido alguna influencia de ellos y, particularmente, de Hans-Hermann Hoppe, en cuya utopía-distopía me detengo al final de este trabajo. ${ }^{4}$ No por nada, Hoppe ha sido, durante los últimos años,

\footnotetext{
${ }^{4}$ Para una explicación acerca de esta "derecha alternativa", su historia y programa, ver Hawley (2018).
} 
uno de los intelectuales "ancla" del Mises Institute (Hawley 2019, 98), uno de los think tanks principales entre los asociados a la derecha más dura en los Estados Unidos. Así, por ejemplo, este sector político tiende a defender ciertas formas de discriminación (en particular, contra minorías sexuales o raciales) del modo en que Hoppe lo hace; esto es, como expresión del legítimo ejercicio del derecho de propiedad.

Como el caso de Hoppe muestra, se ha producido una suerte de simbiosis entre algunas de las utopías que aquí se estudian y esa nueva derecha: las primeras (y particularmente el anarcocapitalismo) ofrecen a la segunda la oportunidad de presentar bajo ropajes nuevos ideas - prejuicios, en realidad - viejas. Los ropajes están tomados del liberalismo libertario, cuyas prendas (derechos, libertades, propiedad, privacidad, etcétera) permiten presentar las reivindicaciones de la "Alt-Right" de modo que resulten, al menos en apariencia, concordantes con los principios de justicia sobre los que se levantan las democracias liberales. De este modo, y en virtud de esa simbiosis, para promover su propia agenda, los partidarios de la "Alt-Right" no necesitan apelar directamente al racismo, la xenofobia, etcétera — lo que a fin de cuentas quedaría mal—, sino que pueden hacerlo de modo indirecto, apelando, por ejemplo, al derecho de propiedad y a la libertad contractual para justificar ciertas formas de discriminación y denunciar la "integración forzada"; a la libertad de expresión para ofender a ciertas personas o grupos; al derecho de familia para, en fin, denunciar programas educativos para sus hijos, etcétera.

Las utopías del derecho privado son funcionales a las políticas identitarias que, con mayor o menor fuerza, informan la "Alt-Right". Por eso tal vez sería más exacto decir, no tanto que el liberalismo libertario ha influido en la "Alt-Right", sino que la "Alt-Right", en personas como Hoppe, ha sabido instrumentalizar esa forma de liberalismo, para presentar sus propias políticas identitarias como expresiones o prácticas legítimas de ciertos derechos individuales. La moraleja de toda esta historia es que - como ya advirtiera el propio Nozick ${ }^{5}$ es mala idea reducir el liberalismo al derecho privado (que es lo que tiende a hacer el libertarianismo) y abandonar, en consecuencia, todos los principios de derecho público.

En cualquier caso, el lector podrá comprobar que la influencia política de los autores aquí estudiados es inversamente proporcional a su

${ }^{5}$ Al respecto, Nozick (1992, 227 y ss). 
importancia intelectual. Hay una gradiente que va de Nozick a Hoppe, tanto por lo que a la sofisticación argumentativa y filosófica se refiere, como a la fidelidad o proximidad a la idea original del liberalismo; es decir, a la idea de que cada individuo debe ser libre para vivir como prefiera, mientras con ello no impida a los demás hacer lo mismo. La gradiente se invierte por lo que toca a la influencia en el ámbito público. Mientras la postura de Nozick es una variante del liberalismo libertario que ha tenido escaso eco en la discusión pública y en el mundo político partidista (si es que ha tenido alguno), el anarcocapitalismo conservador de Hoppe ha tenido no poca repercusión a través de su vinculación con la nueva derecha, representada de manera especial en la ya mencionada "Alt-Right".

Las utopías del derecho privado, y especialmente el anarcocapitalismo, han servido para articular un discurso que combina el liberalismo económico con el conservadurismo moral, salpicado aquí y allá con algo (y a veces no poco) de racismo y xenofobia. El anarcocapitalismo, por inverosímil que suene, ha contribuido a alimentar teóricamente el populismo de derechas, a dotarlo de un discurso, no sólo en Estados Unidos, sino también en Latinoamérica (el caso de Jair Bolsonaro en Brasil resulta ya emblemático a este respecto). Supongo, entonces, que la reconstrucción teórica de su génesis, así como la exposición de sus aspiraciones utópicas pueden servir al lector para hacerse una idea más cabal del trasfondo ideológico que ha alimentado a la "nueva derecha" en Occidente.

\section{LA UTOPÍA FORMAL DE NOZICK Y LAS UTOPÍAS DEL DERECHO PRIVADO}

En la Política, Aristóteles establece como punto de partida de cualquier investigación acerca de la ciudad ideal el problema de cuál es el modo preferible de vida para "todos", "pues mientras esto no esté en claro, tampoco podrá estarlo, forzosamente, el régimen mejor". ${ }^{6}$ Esta

6 "El que se proponga hacer un estudio adecuado del régimen mejor tendrá que definir primero necesariamente cuál es la vida más preferible, pues mientras esto no esté en claro, tampoco podrá estar, forzosamente, el régimen mejor (...). Por eso tenemos que ponernos de acuerdo ante todo acerca de cuál es la vida más preferible, por decirlo así, para todos". Aristóteles, Pol. IV, 1323a14-20. 
pregunta preliminar explica la aparente contradicción envuelta en el intento de formular una utopía liberal. Si se considera, como Aristóteles, que la utopía (en su caso, el estudio de la "ciudad ideal") debe inspirarse en una cierta concepción de la vida buena y de la virtud, entonces la utopía liberal es un oxímoron, en la medida en que el liberalismo busca promover, no la felicidad ni la perfección de los individuos, sino su coexistencia pacífica. Otro tanto ocurre si, con el objetivo de rehuir este problema, se despoja al concepto de felicidad de sus alcances normativos o se lo intenta reemplazar, en fin, por cualquier otra "doctrina comprehensiva" que pudiera servir de fundamento a la utopía. Dicho de otro modo, según el lenguaje al uso, el liberalismo es una doctrina política que da prioridad a lo justo por sobre lo bueno, $y$, sin una concepción sustantiva de lo bueno que sirva de meta a las aspiraciones utópicas y que aúne las voluntades de sus ciudadanos, no parece posible modelar una utopía.

Nozick, por su parte, rechaza la posibilidad de que exista un modo de vida que sea objetivamente mejor para todos y pueda servir para proyectar una utopía:

Wittgenstein, Elizabeth Taylor, Bertrand Russell, Thomas Merton, Yogi Berra, Allen Ginsburg, Harry Wolfson, Thoreau, Casey Stengel, The Lubavitcher Rebbe, Picasso, Moisés, Einstein, Hugh Heffner, Sócrates, Henry Ford, Lenny Bruce, Baba Ram Dass, Gandhi, sir Edmund Hillary, Raymond Lubitz, Buda, Frank Sinatra, Colón, Freud, Norman Mailer, Ayn Rand, el Barón de Rothschild, Ted Williams, Thomas Edison, H. L. Mencken, Thomas Jefferson, Ralph Ellison, Bobby Fischer, Emma Goldman, Piotr Kropotkin, usted y sus padres. ¿Existe realmente una sola clase de vida que sea mejor para cada una de estas personas? (1988, 298-299)

Un poco después, añade que "la idea de que hay una respuesta compuesta mejor que todas estas preguntas, una sociedad mejor para todos en la cual vivir, me parece increíble" $(1988,299)$.

Pero, entonces, ¿cómo es posible que el Estado mínimo - la única forma lícita de Estado para Nozick- pueda ser una utopía? ¿Y en qué sentido podría serlo? Podría serlo porque: a) ofrece las condiciones institucionales para ensayar libremente las más diversas formas de 
vida que quepa imaginar, que no sean incompatibles con los derechos equivalentes de todos los demás; y b) puede albergar las diferentes comunidades que florezcan al alero de las diferentes concepciones de bien de sus ciudadanos, mientras no impidan el florecimiento equivalente de otras comunidades. ${ }^{7}$ Dicho de otro modo, el Estado mínimo es la utopía de la posibilidad de todas las utopías. Puede ser una utopía en tanto que "metautopía".

La idea es, entonces, que imaginemos, con Nozick, las posibilidades utópicas del minarquismo, esto es, del Estado mínimo: ciudadanos se agrupan para formar comunidades según su particular concepción común del bien, que acuerdan modificaciones o cambios en las mismas bajo ciertas circunstancias, admiten nuevos miembros, pierden otros, que se unen a otras comunidades, etcétera. Todas las diferentes comunidades que se suceden coexisten, sin embargo, bajo el Estado mínimo, al que, por otra parte - es de suponer-, le guardan lealtad por la libertad que se les concede para desarrollar sus propios proyectos utópicos.

Como se desprende de lo anterior, el Estado mínimo de Nozick es, en primer lugar, una utopía puramente formal, que contiene (o pretende contener) las condiciones bajo las cuales podrían coexistir diferentes utopías particulares. ${ }^{8}$ Por eso, no puede precisarse cabalmente su contenido, o no más allá del que nos proporcionan las diferentes utopías particulares que fuéramos capaces de imaginar. De ahí que, al abordar el problema de la utopía, Nozick básicamente delegue en el lector la tarea de imaginar cómo será su propia utopía particular, dentro del "marco" general trazado por el Estado mínimo, que, en lo fundamental, proscribe la violencia.

Este carácter puramente formal nos permite dilucidar el primer sentido en el que la metautopía de Nozick es, propiamente, una utopía o una aspiración política imposible: en el sentido de abrigar la improbable ilusión de que todas las utopías particulares (lo que, siguiendo a Lucas Misseri (2011), podemos llamar las "microutopías") puedan coexistir y adaptarse al marco institucional del Estado mínimo. Esto es más impro-

${ }^{7}$ El Estado mínimo puede ser una utopía porque en él cada uno puede vivir según su propia utopía, pero “donde ninguno puede imponer su propia visión utópica sobre los demás”. Ver Nozick (1988, 300).

8 "La utopía consistirá en utopías, en muchas comunidades diversas y divergentes en las cuales las personas llevan diferentes clases de vida bajo diferentes instituciones". Ver Nozick (1988, 300). 
bable (o utópico) aún si se repara en el hecho de que esa ilusión equivale a esperar que todas las doctrinas alternativas ( $\mathrm{y}$ tal vez rivales) del liberalismo (teorías perfeccionistas, paternalistas, socialistas, etcétera) se rindieran definitivamente a su hegemonía. Aspirar a la consecución del mejor de los mundos posibles por medio de la privatización total del bien y el fin de las disputas políticas bajo la preeminencia no desafiada y pacífica del liberalismo (libertario) es, seguramente, lo más utópico de la metautopía de Nozick.

El Estado mínimo puede ser también una utopía en el sentido de ofrecer el mejor estado de cosas imaginable, o las mejores condiciones institucionales imaginables, por dos razones fundamentales. Primero, porque ningún otro Estado puede ofrecer a sus ciudadanos mejores oportunidades para vivir, ensayar o recrear sus propias utopías particulares. En él no hay restricciones perfeccionistas o paternalistas y, por tanto, mientras cuenten con socios o colaboradores para ello, cada individuo puede embarcarse en su propia utopía. Este argumento nos conduce inmediatamente a la segunda razón por la cual el Estado mínimo puede ser considerado el mejor Estado imaginable: porque ofrece condiciones inmejorables para el descubrimiento y perfeccionamiento de las utopías. El Estado mínimo y el principio de la adhesión voluntaria crean condiciones institucionales que reproducen el principio de ensayo y error o el mecanismo de evolución por adaptación; esto es, las comunidades aparecen y desaparecen según sepan interpretar los anhelos de los individuos que participan en ellas. Las comunidades exitosas crecerán, prosperarán o serán imitadas; las otras se reducirán o serán abandonadas; otras rectificarán uno o varios aspectos de su organización, etcétera. Si es posible algún progreso por lo que al descubrimiento de la sociedad ideal se refiere, permitiría descubrirlo la acción conjunta de los mecanismos de diseño y de filtro que el Estado mínimo y el principio de adhesión voluntaria propician.

Ahora bien, ¿cuáles son las condiciones de la coexistencia de las comunidades utópicas a las que nos hemos referido?

Nozick quiere que la metautopía sirva como un argumento adicional e independiente de otros ofrecidos en $A S U$ en favor del Estado mínimo. Más allá de si resulta suficiente para ese propósito, es claro que la independencia argumental de la metautopía no se extiende a lo que podríamos considerar las premisas o presupuestos más generales de 
$A S U$ : las restricciones libertarias. Estas restricciones (que podríamos llamar también "derechos naturales libertarios") son el resultado de la aplicación de las restricciones morales indirectas (es decir, derechos naturales) al campo político, que para Nozick tiene que ver con la delimitación de la esfera de libertades de cada cual. ${ }^{9}$

Nozick ilustra el contenido y alcance de las restricciones libertarias mediante el símil del espacio moral que rodea al individuo, otorgándole un espacio de inmunidad:

Una línea (o un hiperplano) circunscribe un área de espacio moral alrededor de un individuo. Locke sostiene que esta línea se determina por los derechos naturales de un individuo, los cuales limitan la acción de los otros. $(1988,65)$

Un poco después añade:

Una persona, voy a suponer, puede decidir hacerse a sí misma cosas que traspasarían los límites que rodean al espacio moral de su persona si fueran hechas por cualquier otra sin su consentimiento (...). El consentimiento voluntario abre la frontera para cruzar. (...) Mi posición no paternalista sostiene que alguno puede decidir (o permitir a otro) hacerse a sí mismo cualquier cosa, salvo que haya adquirido la obligación ante cualquier tercero de no hacerlo o no permitirlo. $(1988,66-67)$

El señorío que cada uno tiene sobre sí, y que Nozick ilustra con la imagen del hiperplano, puede explicarse con el concepto de la propiedad sobre sí mismo, pues ese señorío es tan amplio y extenso como el que tiene el propietario sobre el bien de su propiedad, es decir, ilimita$d o$. En virtud de él, cada uno puede hacer consigo o de sí lo que desee, mientras con ello no afecte, impida u obstaculice la libertad equivalente de otros (es decir, el disfrute de la propiedad que otros tienen sobre sí mismos). Como en el caso de la propiedad, además, se trata de un derecho de uso y goce exclusivo (corresponde a su titular y nadie más), que autoriza a disponer sin límites sobre sí mismo. Eso incluye, en la

${ }^{9}$ Así se desprende de su caracterización de la filosofía política: "La filosofía política se ocupa únicamente de ciertas formas en que las personas no pueden usar a los demás; primordialmente: agresión física contra ellos” (Nozick 1988, 44). 
concepción de Nozick, la posibilidad incluso de venderse como esclavo $(1988,317)$.

El funcionamiento del marco constitucional bajo el cual funciona la metautopía de Nozick presupone o refleja, entonces, el señorío que cada uno tiene sobre sí mismo. La propiedad sobre sí mismo abre oportunidades para la experimentación de los ciudadanos, al tiempo que fija los límites del deseo utópico, pues proscribe lo que Nozick denomina el "imperialismo" utópico; esto es, la imposición de la propia utopía a otros $(1988,307)$.

Ahora bien, precisamente porque el marco de la metautopía es libertario, "las comunidades individuales dentro de ella no necesitan ser así" $(1988,308)$. En el ejercicio de los derechos que se siguen de la propiedad que cada uno tiene sobre sí, los individuos bien pueden fundar o sumarse a comunidades no libertarias (socialistas, por ejemplo) o a comunidades que tengan estatutos paternalistas o perfeccionistas (como podrían ser algunas comunidades y sectas religiosas). Si se admite, como Nozick, que la propiedad que cada uno tiene sobre sí mismo le autoriza a venderse como esclavo, entonces debe admitirse la posibilidad menos extrema de que, dentro del marco, existan comunidades que, por ejemplo, exijan a sus miembros la renuncia al derecho de abandonarla o, en fin, que exijan se delegue en ellas grados importantes de la propia autonomía. Y todo ello sin contar con que debería admitirse la posibilidad de que existan comunidades que efectivamente alberguen esclavos.

En este punto, la metautopía de Nozick resulta problemática. ¿No podría estimarse que la libertad (es decir, la capacidad jurídica) es irrenunciable? Después de todo, es un contrasentido renunciar a aquello en virtud de lo cual puedo celebrar acuerdos. Otro tanto puede decirse del supuesto paternalismo de la prohibición de enajenar la propia libertad: ¿es acertado calificar esa prohibición como "paternalista"? Con todo, no todas las renuncias a la propia libertad son tan radicales como la de la esclavitud voluntaria. Para aquellos casos menos extremos, ¿dónde debemos trazar la línea que separa las renuncias aceptables de las no aceptables?

Seguramente podría objetarse a la "postura no paternalista" de Nozick que la aceptación de la enajenación voluntaria de la propia personalidad socava las bases de la propia utopía libertaria: a la larga, 
las enajenaciones de la personalidad que por una u otra razón ocurran (necesidad, inmadurez, condicionamiento cultural, etcétera) producirán zonas de dominación y servidumbre, que desfigurarán el semblante utópico (en el sentido ahora de "deseable") del Estado mínimo.

Los peligros de esta potencial deriva distópica de la utopía de Nozick - peligro que, por lo demás, acecha a cualquier utopía $-{ }^{10}$ ponen de manifiesto un problema más general del liberalismo, que tiene que ver con el grado de tolerancia que debe tener hacia las concepciones paternalistas o perfeccionistas y, más allá de ellas, hacia las concepciones derechamente hostiles a la libertad. Este problema queda reflejado, por ejemplo, en la denominada "paradoja de la tolerancia" de Popper o los debates acerca de la "neutralidad" del liberalismo frente a aquellas posiciones o doctrinas que exigen se reconozca la libertad para adoptar, enseñar, difundir, etcétera, el paternalismo y el perfeccionismo.

En cualquier caso, es claro que para Nozick las comunidades paternalistas y perfeccionistas y, en general, antiliberales no pueden invocar el marco constitucional del Estado mínimo para evitar darles a los niños una educación que impida el desarrollo gradual de su autonomía. Por este motivo, sostiene Nozick que "los niños representan problemas aún más difíciles. De alguna manera, tiene que garantizarse que ellos están informados de las clases de alternativas que hay en el mundo" (1988, 317). ${ }^{11}$ La necesidad de informar a los niños se sigue de que la propiedad que los padres tienen sobre sí mismos no se extiende a los niños. Los hijos son seres diferentes y separados de sus padres. Sus padres no son sus propietarios. En consecuencia, la educación que les den debe ser tal que no impida a los niños el ejercicio futuro del derecho de propiedad que tienen sobre sí. Los niños deben poder llegar a ser adultos que vivan su propia vida. Pero, ¿cómo se resguardará ese derecho de los niños? Nozick no menciona ni las medidas ni las instituciones que debería adoptar el Estado mínimo con vistas a la protección de la auto-

${ }^{10}$ Ver Schwember y Urabayen (2018).

${ }^{11}$ Okin ha llamado la atención acerca de la dificultad que Nozick tendría para justificar el derecho independiente de los niños. Ciertamente, Nozick no explica por qué los niños no son propiedad de sus padres, que los fabricaron (y, particularmente, de sus madres). De ser ése el caso, la utopía de Nozick podría derivar en un matriarcado distópico. Comparar Okin (1989, 74 y ss.). El pasaje citado de $A S U$ revela, sin embargo, que no cree que los niños sean propiedad de sus padres. 
nomía de los niños. ${ }^{12}$ Sin embargo, como él mismo afirma, no hay que esperar descripciones exhaustivas de todos los aspectos de una utopía. Algunos de esos aspectos quedarán apenas pergeñados. Es de suponer, podría añadirse, que el atractivo de las utopías descansa en parte en esa inconclusión.

\section{EL DEBILITAMIENTO DEL MARCO: LA UTOPÍA DE LA TOLERANCIA DE KUKATHAS}

El problema de los niños en que repara Nozick apunta a la disyuntiva que Kukathas formula en oposición a Kymlicka entre autonomía y tolerancia:

Un régimen liberal es un régimen de tolerancia. Apoya normas de tolerancia no porque valore la autonomía sino porque reconoce la importancia del hecho de que la gente piensa diferente, ve el mundo de modo diferente y está inclinada a vivir —o incluso piensa que debe vivir - de forma diferente al modo en que otros creen que deberían hacerlo. Defiende la tolerancia a través de la protección de la libertad de asociación, para que la gente puede vivir como ella piensa que debe hacerlo, como su conciencia le dicta. (Kukathas 2003, 39) ${ }^{13}$

En la utopía libertaria pueden prosperar las comunidades no libertarias o, incluso, antilibertarias. Pero, ¿hasta qué punto? Kukathas imagina dos posibilidades, que dan lugar a dos clases de libertarianismo: el de la autonomía y el de la tolerancia. Cada uno ofrece una respuesta diferente a esta pregunta (Kukathas 2009).

Conforme al primero, se entiende que el respeto de los principios libertarianos de propiedad y de no agresión no son optativos. Todas las

${ }^{12}$ Pero, ¿no requeriría esto la introducción de alguna forma de instrucción obligatoria? ¿Y no convertiría esto al Estado en un Estado más que mínimo?

13 "A liberal regime is a regime of toleration. It upholds norms of toleration not because it values autonomy but because it recognizes the importance of the fact that people think differently, see the world differently, and are inclined to live - or even think they must live- differently from the way others believe they should. It upholds toleration because it respects liberty of conscience. It upholds toleration by protecting freedom of association so people can live as they think they should, as conscience dictates". 
comunidades (incluso las no libertarias) deben respetarlos. Por eso, en lo que podemos denominar la utopía libertaria de la autonomía, "a nadie se le permite vivir sin libertad, a menos que haya explícitamente renunciado a aquellas libertades particulares de que carece" (Kukathas $2009,8)$. Pero eso significará que, en la utopía de la autonomía, "ciertas clases de asociaciones o comunidades no pueden existir, pues las únicas asociaciones legítimas son las asociaciones voluntarias" (Kukathas 2009, 8).

Obviamente, las comunidades que no pueden prosperar dentro de la utopía libertaria de la autonomía son aquellas que inculcan una educación que forma a sus miembros en, digamos, la heteronomía, proscriben estilos de vida por motivos puramente paternalistas o naturalizan ciertas posiciones sociales y culturales que coartan la libertad individual de algunos de sus miembros (como, por ejemplo, aquellas que mantienen a las mujeres en una situación de subordinación o criminalizan o estigmatizan a las minorías sexuales).

En estos casos, el marco constitucional de la sociedad libertaria se preocupará, por ejemplo, de informar a los niños que existen otras alternativas que aquella que se les enseña en sus comunidades de origen, o de impedir prácticas que atentan contra la integridad moral o física de los menores de edad, aun cuando dichas prácticas formen parte de tradiciones ancestrales, etcétera. Después de todo, si los hijos son personas diferentes de sus padres y tienen su propia vida que vivir, la sociedad libertaria debería disponer las medidas que les permitan finalmente vivirla.

En la utopía libertaria de la tolerancia, en cambio, se entiende que los principios libertarios se aplican a las relaciones entre las diferentes comunidades y no (o no necesariamente) a los individuos particulares. Esto supone que las comunidades tienen una amplia autoridad (o, mejor, "jurisdicción") sobre sus miembros y que, en consecuencia, "la sociedad buena que la teoría política liberal describe no es una entidad unificada" (Kukathas 2003, 20). Por eso, la imagen con la que Kukathas describe su utopía liberal es la de un archipiélago cuyas islas son las comunidades que flotan en un mar de tolerancia:

El archipiélago liberal es una sociedad de sociedades, que ni es la creación ni es objeto de control de ninguna autoridad. Es una sociedad en que las autoridades funcionan bajo leyes que están 
por sí mismas más allá del alcance de cualquier poder singular.

$(2003,22)$

La utopía liberal de la tolerancia de Kukathas refleja la convicción de que "el principio fundamental que describe a una sociedad libre es el principio de libertad de asociación"; de él se siguen, como corolarios suyos, "el principio de libertad de disociación" y "el principio de tolerancia mutua de las asociaciones" $(2003,4)$.

Pero, ¿es realmente la utopía de la tolerancia de Kukathas una utopía liberal (o libertaria)? Tal vez la principal razón para desechar la posición de que verdaderamente lo sea radica en el hecho de que los principios libertarios se apliquen a las asociaciones y no necesariamente a las personas. Sin embargo, Kukathas siempre podría replicar que, pese a eso, la suya es una utopía liberal porque defiende "el derecho a dejar la comunidad" (right to leave) (Kukathas 2003, 96). Más aún, este derecho no sólo es esencial a la utopía de Kukathas por razones conceptuales, sino también porque sirve para explicar la legitimidad de las autoridades de las comunidades: dichas autoridades son legítimas en la medida en que las personas que se encuentran bajo su jurisdicción decidan permanecer bajo la misma.

Ese derecho de salida recuerda la justificación del poder político que da Locke a partir del consentimiento tácito de los súbditos. ${ }^{14}$ Está, por lo mismo, expuesto a dificultades semejantes. Por ejemplo, a la crítica que Hume hiciera al argumento del consentimiento tácito de las teorías contractualistas: los supuestos requeridos para el ejercicio del derecho a abandonar un país son en la mayoría de los casos ilusorios (Hume 2006, 105). ${ }^{15}$

Más allá de las dificultades asociadas al ejercicio del derecho de salida, la utopía de Kukathas podría sostenerse diciendo que la tolerancia de las comunidades opresoras (incluyendo a aquellas que retienen gente contra su voluntad) es un mal menor en comparación con el despliegue de autoritarismo que supondría el intento por desterrarlas o reformarlas. Dicho de otro modo, la política de la tolerancia es siempre mejor (o menos mala) que las políticas que reivindican la autonomía

${ }^{14}$ Locke, Segundo tratado $\$ 119-122$.

${ }^{15}$ Kukathas se hace cargo de varias objeciones al "exit principle" en Kukathas (2003, 103 y ss.). 
contra la conciencia de aquellos que se oponen a ella. Kukathas avanza por esa línea de razonamiento cuando afirma que la política de la tolerancia:

bien puede permitir dentro de la sociedad más amplia a una serie de comunidades cohesionadas pero opresivas: islas de tiranía en un mar de indiferencia. No obstante, es preferible la descentralización de la tiranía. Una razón para preferirla es que mientras todo poder tiende a corromper, el poder absoluto corrompe absolutamente. $(2003,137)^{16}$

Este argumento ofrece una defensa de toda la construcción teórica de Kukathas, al tiempo que evita (y denuncia) los riesgos de un eventual imperialismo o colonialismo cultural libertario, que obligara a las comunidades iliberales a adoptar coactivamente principios libertarios. ${ }^{17}$

La utopía de Kukathas puede entenderse como una reinterpretación del alcance de la afirmación de Nozick de que cada individuo debe ser libre para poder vivir su propia vida (Nozick 1988, 60). Kukathas entiende que eso significa, en lo fundamental, que cada uno pueda vivirla de acuerdo con sus propias convicciones (libertad de conciencia), y que esas convicciones le deben permitir formar y participar de las asociaciones que prefiera (libertad de asociación). Desde el punto de vista institucional, esas libertades se traducen en el rechazo del Estado mínimo y del marco metautópico de Nozick, por los riesgos y desventajas que, a su juicio, ese tipo de Estado entraña (Kukathas 2009 y 2011).

En cualquier caso, las razones para escoger entre una utopía y otra son, paradójicamente, desalentadoras, pues Kukathas cree que estamos condenados a tener que elegir entre dos formas de tiranía. La razón última para preferir la utopía de la tolerancia por sobre la utopía de la autonomía es que, pese a todo, la primera sería menos mala que la segunda.

16 "May well leave within the wider society a number of cohesive but oppressive communities: islands of tyranny in a sea of indifference. Nonetheless, the decentralization of tyranny is to be preferred. One reason to prefer it is that while all power tends to corrupt, absolute power corrupts absolutely".

${ }^{17}$ Con todo, en un universo libertario aún cabría imaginarse "justicieros" (o incluso grupos de "justicieros") que, en ejercicio del derecho lockeano de salvar a los inocentes y castigar las transgresiones a la ley natural, asaltaran las comunidades opresoras para liberar a las personas injustamente retenidas en ellas. Kukathas es consciente de este riesgo, naturalmente. Ver Kukathas $(2009,6)$. 
Aunque ése fuese el caso, es importante advertir las consecuencias que se siguen de esa elección que diluye el marco de la metautopía de Nozick: la dispersión del poder y de las funciones judiciales, el pluralismo jurídico y, en fin, la virtual desaparición de la igualdad natural de los individuos en las islas de tiranía de las comunidades opresoras. Así las cosas, el debilitamiento del "marco" descrito por Nozick conduce, en la propia lógica libertaria, a una sociedad cuyo semblante empieza a recordar al feudalismo. La única razón por la cual las "islas de tiranía" de Kukathas no son todavía un sistema feudal es por el derecho de salida. Los siervos de la gleba, en cambio, no tenían ese derecho.

\section{LAS DISTOPÍAS ANARCOCAPITALISTAS Y LA DERIVA FEUDALISTA}

En la utopía de Nozick, el derecho público aún tiene un modesto pero crucial papel que desempeñar a través del marco constitucional del Estado mínimo. Aunque Nozick no especifica el alcance ni el funcionamiento del marco, es claro que su existencia podría impedir -o al menos entorpecer- la realización de ciertas microutopías iliberales, que atentaran o menoscabaran la libertad individual.

Por limitada —e insuficiente — que sea su acción, la existencia del marco del Estado mínimo, incluidos los escuetos principios de derecho público que supone, hace una diferencia y distingue la metautopía de Nozick de lo que podemos denominar las "utopías puras del derecho privado", en que todo vestigio de derecho público ha desaparecido. Las teorías anarcocapitalistas ofrecen el mejor ejemplo de este tipo de utopías, pues ellas mismas resultan de depurar el libertarianismo de las trazas de derecho público que todavía pudiera contener. ${ }^{18}$ Por lo demás, el anarcocapitalismo comparte las premisas del libertarismo: propiedad sobre sí mismo, principio de no agresión y origen convencional de las obligaciones jurídicas positivas (es decir, de aquellas que no se reduz-

${ }^{18}$ De todos modos, es preciso admitir que los libertarios siempre intentan dar cuenta del derecho público mediante las explicaciones o categorías del derecho privado. El argumento de Nozick a favor del Estado mínimo hace, en efecto, eso: intenta mostrar cómo una autoridad pública, con el monopolio de la fuerza, podría legítimamente surgir a partir de acuerdos privados y la aplicación de ciertos criterios de derecho contractual, derecho de daños y responsabilidad extracontractual. 
can al deber de respetar la propiedad de otro e impongan, en cambio, la realización de alguna prestación u obligación positiva). Asimismo, los autores anarcocapitalistas tienden a identificar "involuntariedad" con "coacción": si no ha habido coacción ilegítima (que es precisamente la que el principio de no agresión proscribe), las acciones de los agentes deben tomarse como voluntarias.

De todo esto se siguen los principios sobre los que se levantan las utopías puras del derecho privado (anarcocapitalistas), entre los cuales resultan fundamentales los siguientes:

a) La propiedad como modelo de todos los demás derechos subjetivos Lo que podríamos denominar la formulación canónica de la propiedad sobre sí mismo se encuentra en el § 27 Segundo tratado del gobierno civil, en el que Locke afirma que "cada hombre tiene (...) una propiedad que pertenece a su propia persona; y a esa propiedad nadie tiene derecho, excepto él mismo. El trabajo de su cuerpo y la labor producida por sus manos podemos decir que son suyos". Como Locke, los libertarios y anarcocapitalistas procuran derivar de ese derecho originario y natural sobre sí mismo los otros derechos adquiridos (podríamos decir "naturales adquiridos", siguiendo a Kant). Concretamente los ius in rem y los ius in personam, es decir, los derechos sobre las cosas o a la conducta de algunas personas. Por esta razón, se puede afirmar, con Narveson, que "la tesis libertaria es en realidad la tesis de que un derecho a nuestras propias personas como nuestra propiedad es el único derecho fundamental que existe" $(2001,71)$.

Sin embargo, los autores libertarios y anarcocapitalistas van más lejos que Locke y sostienen que todos los derechos subjetivos son especies o formas de la propiedad sobre sí mismo. Por eso, Narveson afirma también que "la insinuación de que existan 'derechos de otras clases' además de los derechos de propiedad es bastante engañoso" $(2001,71) .{ }^{19}$

${ }^{19}$ Comparar también Rothbard: "but in the profoundest sense there are no rights but property rights" (1977, 238); "the concept of 'rights' only makes sense as property rights" $(1998,113)$ y Hoppe $(2007,200)$ : “all human rights are property rights, and all human rights violations are property rights violations". 
Esta concepción es muy importante, porque todo lo que no pueda ser reivindicado a la manera en que se reivindican los bienes materiales, o todo lo que no pueda ser usado de modo exclusivo, por regla general, no es para esos autores un verdadero derecho. Lo que pueda serlo, por su parte, lo será al modo de la propiedad. Por eso son frecuentes los esfuerzos entre ellos por explicar o delimitar todas las libertades y derechos a partir del modelo que ofrece el derecho de propiedad y sus condiciones de aplicación. Así, por ejemplo, Walter Block sostiene que la reputación (lo que jurídicamente podríamos denominar el "derecho a la honra") no es algo "que se pueda poseer", pues "es lo que otros piensan de él; consiste en los pensamientos que otros tienen" (Block 2012, 92-93). A partir de aquí Block concluye que "el escarnio y la calumnia son consistentes con la libertad de expresión" $(2012,94)$.

b) Alienabilidad de los derechos

Con todo, aquí hay grados. Como hemos visto, Nozick admite la posibilidad de venderse como esclavo, mientras que, por ejemplo, Rothbard (1995, 41; 134-135) y Hoppe $(1987,99)$ afirman que un contrato de esclavitud es nulo y carece de todo valor jurídico. No obstante, puesto que la propiedad es el derecho a partir del cual se orientan los libertarios y anarcocapitalistas para comprender los derechos, la alienabilidad de los derechos es la regla general. Por eso, fuera del caso de la esclavitud, los libertarios y anarcocapitalistas admiten la posibilidad de disponer de sí mismo, del propio cuerpo y de los propios bienes sin restricciones. La total libertad contractual es el resultado de esta alienabilidad y el modo, asimismo, de realizarla.

c) La no coacción como condición necesaria y suficiente de la voluntariedad

Básicamente, para los libertarios y anarcocapitalistas, todo aquel que no es víctima de coacción ilegítima obra voluntariamente. Por tanto, el que las opciones de una persona estén "severamente limitadas" (Nozick 1988, 255), no impide que su acción (o, más exactamente, las elecciones entre los cursos de acción que le queden) sea libre. Si esa limitación se debe a los hechos de la naturaleza, "las acciones son voluntarias"; si se debe, en cambio, a las ac- 
ciones de otras personas, la acción de esa persona será voluntaria si es que esas otras personas "tenían el derecho a actuar como lo hicieron" (Nozick 1988, 255). Esta distinción entre las limitaciones originadas en la naturaleza y en la acción de otras personas es importante, pues permite distinguir entre "libertad" y "poder". La confusión entre ambas, dice Rothbard, conduce a absurdos (1977, 42). Sólo las segundas pueden coaccionarnos y, por tanto, privarnos de nuestra libertad.

Ahora bien, es preciso, sin embargo, advertir que hay diferencias en las definiciones de coacción entre los autores libertarios y anarcocapitalistas. Nozick, por ejemplo, que tiene una concepción de coacción parecida a la de Hayek, que incluye las amenazas y otras formas de presión, llega a decir que "aunque la coacción está íntimamente ligada a la libertad (de hecho, para ciertos autores la libertad se reduce a la ausencia de coacción), no por ello equivale a dicho término" (Nozick 1999, 27). Rothbard, en cambio, simplemente define "libertad" (freedom) como la "ausencia de invasión de la persona o de la libertad de un hombre a manos de otros hombres" $(1995,78)$. Desde este punto de vista, el que alguien tenga que escoger en condiciones muy adversas, o apremiado incluso por la necesidad, no significa que debamos considerar sus acciones como involuntarias o no queridas (o cualquier otra categoría que permitiera introducir algún matiz). Por eso, por ejemplo, Block puede decir que "la vida de una prostituta es tan buena o tan mala como ella quiere que lo sea. Se mete a prostituta voluntariamente, y es libre de dejar de serlo cuando quiera" (Block 2012, 35).

d) Inexistencia de bienes públicos o apropiabilidad universal de los bienes

Al momento de discutir acerca de la conveniencia de la propiedad y el "comunismo platónico", Aristóteles advierte tres posibilidades teóricas: que todas las cosas sean comunes, que todas sean privadas o, en fin, que algunas sean comunes y otras privadas. Desecha la segunda porque, dice, es imposible que todo sea privado, pues al menos el lugar en que se asienta la ciudad es común. ${ }^{20}$ El liber- 
tarismo y el anarcocapitalismo pueden ser definidos como la negación de esta afirmación aristotélica de la imposibilidad de la privatización universal de los bienes. Los alcances de esta privatización universal de los bienes dependerán, en buena medida, sin embargo, de si los autores anarcocapitalistas admiten o no la estipulación de Locke. Esta estipulación permite el uso de bienes ajenos en ciertos casos. ${ }^{21}$ Nozick cree que la inclusión de la estipulación de Locke es necesaria para la justificación de la propiedad. Rothbard y Hoppe no lo creen así. ${ }^{22}$

\section{e) Carácter privado de los vínculos políticos y neofeudalismo}

Samuel Freeman ha sostenido que, pese a sus aparentes similitudes, el libertarianismo y el anarcocapitalismo no son filosofías liberales. Una de las razones que esgrime es: "Como el feudalismo, el libertarismo concibe la justificación del poder político como una basada en una red de contractos privados. Rechaza la idea, esencial al liberalismo, de que el poder político es un poder público, imparcialmente ejercido para el bien común" (Freeman 2018, 63).

${ }^{21}$ Más concretamente, lo permite cuando una apropiación ha empeorado la situación de una persona. En tal caso, el afectado puede usar el bien de aquel cuya apropiación lo puso en esa situación desventajosa. Nozick introduce su interpretación de la estipulación de Locke (1988, 175-183). Para las estipulaciones del propio Locke, comparar los $\S \S 31$ y 33 del Segundo tratado del gobierno civil. La literatura acerca de la estipulación de Locke es enorme. Un mapa general de las diferentes interpretaciones de la misma se encuentra en Widerquist (2010). En cualquier caso, la estipulación fue concebida por Locke como una forma de justificar la propiedad sin necesidad de tener que recurrir a un contrato social o contrato originario en el cual o por el cual ésta fuera instituida.

${ }^{22}$ Una de las líneas divisorias entre el así llamado "Right-libertarianism" y el "Left-libertarianism" se puede trazar a partir del lugar que tiene o se le otorga a la estipulación de Locke en una teoría: si la admiten o no, de qué modo y hasta qué punto. Los "libertarios de derecha" no admiten la estipulación o admiten una versión muy débil de la misma. Fuera de los anarcocapitalistas aquí referidos, se encuentran entre ellos, por ejemplo, Narveson (2001) y Feser (2005). Los "libertarios de izquierda", en cambio, tienden a interpretar la estipulación en un sentido fuerte, que inclina el libertarianismo hacia el liberalismo igualitario. Entre estos últimos se encuentran Van Parijs (1996), Otsuka (2003), Vallentyne y Steiner (2000) y Roark (2013). Una introducción al "Left-libertarianism" a través de una antología de textos representativos se encuentra en los dos volúmenes publicados por Vallentyne y Steiner en el 2000, y que se consignan en la bibliografía final. 
Una prueba del carácter privado de los vínculos políticos es el desvanecimiento del concepto de ciudadanía en las teorías libertarias. Ese desvanecimiento se produce porque "los libertarianos piensan que la ciudadanía en un Estado es casi tan significativa desde un punto de vista moral como la membresía en una compañía aseguradora de autos" (Hidalgo 2017, 381). En consecuencia, nadie por principio es miembro de una asociación política y, por lo mismo, en un mundo libertario podría haber individuos que carecieran de pertenencia a cualquier comunidad política. Podría ocurrir también que la pertenencia a alguna comunidad sea pagada o dependa del cumplimiento de ciertos requisitos arbitrarios (como los que se pueden exigir para obtener la membresía de un club). Podría suceder, por último, que un solo individuo, que fuera propietario del asentamiento en el que muchos conviven, dicte unilateralmente todas las reglas que rigen la vida común y que ninguno de los comuneros tuviera ningún derecho ni para discutir ni para modificar ni oponerse a esa decisión del propietario.

El que la ciudadanía — entendida como el igual derecho a participar en las deliberaciones y votaciones que regulan la vida común- no sea por principio universal permite que se introduzcan sistemas de castas o de estatus, al menos en la medida en que ellos sean compatibles con la propiedad de cada uno sobre sí mismo. En consecuencia, en las sociedades libertarias es posible suponer que, fuera de los derechos naturales, los individuos podrían tener derechos civiles y políticos de muy distinto tipo, según la habilidad que posean para granjearse el respeto de otros o, tal vez, según la capacidad que tienen para comprar esos derechos. ${ }^{23}$

En consecuencia, y en virtud de la aplicación de los principios precedentes, es posible imaginar la existencia de vastos territorios cuyos propietarios (tal vez grandes corporaciones o multinacionales) se comportan y tienen el estatus de verdaderos señores, que gobiernan a

23 Obviamente, sólo se pueden comprar las muestras meramente exteriores de reconocimiento y respeto. Por eso podría decirse que, en la medida en que se los entrega y reduce a esas muestras puramente exteriores, el anarcocapitalismo y el libertarianismo más duro falsean tanto el respeto como el reconocimiento que recíprocamente se deben los conciudadanos. 
diferentes grupos de individuos que conviven en su territorio, pero pertenecen a diferentes castas, reguladas por diferentes estatutos, según los derechos que les han cedido.

Así las cosas, podemos completar la comparación de Freeman entre libertarianismo (o algunas de las formas del mismo) y feudalismo. Para ello podemos recurrir a la caracterización que del feudalismo ofreciera Ganshof, que reza del siguiente modo:

Se puede concebir el feudalismo como un tipo de sociedad cuyos caracteres determinantes son: un desarrollo elevado a grandes extremos de los lazos de dependencia de hombre a hombre, con una clase de guerreros especializados que ocupan los peldaños superiores de dicha jerarquía; una fragmentación extremada del derecho de propiedad; una jerarquía de los derechos sobre la tierra nacidos de dicha fragmentación, jerarquía que corresponde a la misma jerarquía en los lazos de dependencia personal que acabamos de mencionar; una fragmentación del poder público que crea en cada país una jerarquía de instituciones autónomas, que ejercen en interés propio los poderes atribuidos normalmente al Estado y a menudo la misma fuerza efectiva de éste en una época anterior. (Ganshof 2019, 15-16)

En las utopías del derecho privado, los lazos de dependencia podrían tenerse respecto de un gran propietario o de una corporación; estos últimos, junto con los gerentes y grandes accionistas, se ubicarían en la cúspide de la organización social. La propiedad de sí estaría igualmente dividida en virtud de los diferentes acuerdos que todos tendrían que celebrar para regular los distintos aspectos de la vida social. Es de suponer, entonces, una gran dispersión de derechos de los clientesconsumidores-empleados; esa dispersión es correlativa a la concentración de varios paquetes de esos derechos en manos de algunos grandes señores o propietarios. El porcentaje de participación en esos mismos paquetes determinaría el lugar en la jerarquía social (los que tienen más acciones deciden más cosas), así como la extensión de los derechos de cada cual. Es posible imaginar, también, que los derechos de diferentes señores o corporaciones se superponen y que, eventualmente, hay controversias acerca de lo que cada una puede exigirle a un individuo particular (por ejemplo, las aseguradoras de salud pueden prohibirle a un individuo ciertas cosas, mientras que su trabajo le exige otras, 
más o menos incompatibles con aquéllas). El poder, en este sentido, se dispersa. Pero, en cualquier caso, sus titulares lo ejercen en su propio beneficio.

Este estado hipotético de cosas, que tiene ciertos parecidos con el feudalismo histórico, bien podríamos denominarlo "neofeudalismo". ${ }^{24}$

\subsection{Rothbard, Block y algunos de los supuestos implícitos de la utopía anarcocapitalista}

¿Cómo sería más concretamente la sociedad si se aplicaran sistemáticamente los principios anarcocapitalistas? Dejémonos guiar por las ocurrencias de Rothbard y Block, y exploremos algunos aspectos de la sociedad que ellos imaginan.

Lo más importante es que se acabaría el Estado. Con ello se acabarían también todos los programas de redistribución de la riqueza (por ejemplo, a través de los programas de seguridad social). ${ }^{25}$ En lo sucesivo, cada uno obtendría tanto como puede conseguir a través de

${ }^{24}$ Uno de los evaluadores anónimos de este trabajo me invitaba a referirme al caso de "Left-Libertarianism"; concretamente, a que abordara el problema de si acaso dicha corriente está expuesta a la deriva distópica del "Right-Libertarianism" que aquí describo. La pregunta es muy pertinente pues, como ese mismo evaluador observa, ambas clases de libertarianismo parten de las mismas premisas. Pues bien, creo que la respuesta a esa pregunta es: "No, el libertarianismo de izquierdas no está expuesto a esta particular distopía neofeudalista”. La razón de ello se encuentra en la particular interpretación que los libertarios de izquierdas hacen de las premisas del libertarianismo. Así, mientras, por ejemplo, los libertarios de derecha interpretan las libertades que concede el "self-ownership" de modo puramente formal, los libertarios de izquierda las entienden de modo material; mientras los primeros asumen (con razón, hay que decir) que en un principio los bienes carecen de dueño, los segundos parten de alguna forma de comunidad originaria positiva; otro tanto sucede con la estipulación de Locke, que resulta de especial importancia para atajar ciertas derivas distópicas que pueden seguirse del libertarianismo. En virtud de lo anterior, los libertarios de izquierda aceptan y defienden, por ejemplo, impuestos altos, distribuciones más o menos igualitarias de los recursos o la inapropiabilidad de ciertos bienes. Todo ello los lleva a promover sus propias utopías (la renta básica universal es seguramente la más característica), que de seguro están expuestas a sus propias derivas distópicas. La narración de esa deriva (o posible deriva) deberá quedar, me temo, para otra ocasión.

25 "Al régimen de libertad pura —a la sociedad libertaria - se lo puede describir como una sociedad en la que no se 'distribuyen' los títulos de propiedad" (Rothbard 1995, 77). 
los acuerdos celebrados con otros. Pese al probable trauma inicial, no habría que temer que a la larga se multiplicaran los desposeídos, marginados o menesterosos, pues, liberadas de los impedimentos estatales, las fuerzas creativas de la iniciativa privada producirían un mundo tan desigual como próspero. Esa prosperidad - que seguramente no sería otra cosa que el "enorme cúmulo de mercancías" (Marx 2012, 43), que produce el capitalismo - conjuraría las penurias de los necesitados.

Este supuesto —el de la prosperidad y, más aún, el de la prosperidad indefinida y universal - es necesario para evitar dos derivas distópicas obvias de una teoría política que cree que las medidas redistributivas son esencialmente un robo: i) la ruina de aquellos que padecen necesidad, y ii) la explotación de aquellos que han contratado apremiados por la necesidad. Más concretamente, sólo bajo ese supuesto - que constituye lo que podemos denominar la utopía económica implícita y auxiliar del anarcocapitalismo - se puede entender que los anarcocapitalistas rechacen la estipulación de Locke/Nozick, que autoriza el uso - y no la apropiación, como erróneamente entiende Rothbard (1995, 330 ) - de los bienes ajenos en ciertos casos de necesidad, ${ }^{26}$ y que tengan por justos (e incluso ventajosos) los contratos celebrados bajo estado de necesidad o en condiciones de precariedad.

Vamos al primer caso, el rechazo de la estipulación de Locke/Nozick. Aun suponiendo que la fe anarcocapitalista en la eficacia del mercado para erradicar la necesidad es cierta, existen situaciones (accidentes, casos de fuerza mayor, etcétera) que esa presunta eficacia no puede resolver. Piénsese en el caso del náufrago que necesita pisar tierra en una isla que ya tiene dueño. $\mathrm{O}$ el de un hombre que necesita cruzar por el puente de su vecino para huir de un incendio en su propiedad. O el de la persona extraviada en el desierto que encuentra un oasis que tiene propietario. ¿Cómo deberían tratarse estos casos en una utopía anarcocapitalista que no admite la estipulación de Locke/Nozick o que, en términos más generales, no admite que la propiedad pueda verse nunca superada por otros bienes jurídicos? Una utopía que responde a esta

${ }^{26}$ Existen muchas versiones de la estipulación de Locke. En rigor, la interpretación que de ella ofrece Nozick se aplica a algunos casos de necesidad, no a todos. También se debe aplicar en otros en que mi apropiación causa a otros un empeoramiento que no los deja en estado de necesidad. 
pregunta diciendo que en todos ellos "el dueño tiene derecho a prohibir el uso de sus bienes" es una utopía que se ha autorrefutado.

Extrapolemos ahora estos casos de laboratorio. ¿Qué pasaría en una sociedad anarcocapitalista con aquellos que padecen necesidad por algún accidente (y que no tenían seguro que los cubriera)? Algunos afortunados podrían contar con la ayuda de algún alma caritativa; otros tendrían menos suerte, pero todavía podrían cerrar algunos tratos leoninos a cambio de ayuda (tratos que para todos los efectos serían perfectamente "voluntarios"). Otros simplemente morirían.

Este último ejemplo nos conduce al segundo punto señalado arriba, acerca de la validez de los contratos y acuerdos. En los propios términos de los libertarios y anarcocapitalistas, un contrato es justo porque es voluntario. Volenti non fit iniuria: al que consiente no se le hace daño. El problema, sin embargo, no radica en este principio, sino en que tanto libertarios como anarcocapitalistas parecen decididos a hacer abstracción de las condiciones en y bajo las cuales se aplica. El principio no pone, evidentemente, las condiciones de su propia aplicación, es decir, las condiciones bajo las cuales la voluntad puede efectivamente escoger. Si así fuera, seríamos omnipotentes y no habría necesidad de ninguna teoría de la justicia. Sin embargo, dado que somos finitos, necesitamos de ciertas condiciones materiales para poder identificarnos y no simplemente resignarnos a aquello que escogemos.

Una aplicación que tuviera en cuenta las condiciones bajo las cuales se aplica el principio volenti non fit iniuria — es decir, una aplicación no ideológica del mismo - tendría que admitir que, mientras mayor es la necesidad o más adversas son las condiciones de un contratante, menor es la voluntariedad con la que contrata y que, por consiguiente, menos justo es el acuerdo que cierra. La voluntariedad, como la justicia de los acuerdos, tienen, pues, grados. ${ }^{27}$

El anarcocapitalismo hace abstracción de la necesidad y de los grados de voluntariedad, porque, como decíamos, adopta tácitamente un supuesto utópico. Ese supuesto no es simplemente que el capitalismo aumentará la cantidad de bienes disponibles (que, por lo demás, es una verdad empírica). El supuesto es más fuerte: es que lo hará de tal modo, con tanta eficiencia y con tanta rapidez, que por sí mismo y

${ }^{27}$ Para las implicaciones de la admisión de los grados de voluntariedad en una teoría libertaria, ver Schwember (2018). 
sin la aplicación de ninguna política centralizada, erradicará de modo general la necesidad. Ésta dejará, entonces, de ser un problema (teórico, político y jurídico) para el anarcocapitalismo y para todos los que vivan a su alero. Los demás casos (el náufrago, los accidentes, etcétera) serán lamentables, pero lo suficientemente marginales como para remecer la convicción de la sociedad anarcocapitalista en la supremacía absoluta de la propiedad privada.

Este supuesto utópico, por tanto, es condición general de inteligibilidad del libertarianismo y del anarcocapitalismo, como teorías de la justicia. Piénsese en la afirmación de Block de que la vida de una prostituta es tan buena o tan mala como ella quiere que sea. Esta afirmación es tan evidentemente falsa desde un punto de vista empírico, que el único modo de darle algún sentido (que no sea simplemente decir que no sabe ni es capaz de imaginar las condiciones que empujan a las mujeres a la prostitución, o que no entiende lo que significa "voluntario") es atribuirle a Block la creencia de que, en un mundo anarcocapitalista, la necesidad habría sido erradicada, de modo que en él ninguna mujer tendría que prostituirse para poder ganarse la vida. Todas las que lo hicieran, lo harían, por tanto, únicamente por gusto.

Sin embargo, no es claro que la secreta utopía del éxito del capitalismo en la erradicación de la necesidad sea suficiente para evitar las derivas distópicas de la teoría anarcocapitalista de la familia. ¿Cómo sería esa teoría de la familia?

Por una parte, se permitirían los matrimonios entre personas del mismo sexo, la poliginia, la poliandria, etcétera; por otra, los padres no tendrían ya más obligaciones legales para con sus hijos. Esto significa que los padres

no deberían tener la obligación legal de alimentarlos, vestirlos y educarlos, ya que tales exigencias serían coactivas y privarían a los padres de sus derechos. Por otro lado, estos padres no pueden asesinar o mutilar a sus hijos, y la ley castiga, con toda razón, a quienes lo hacen. Pero a los padres les asistiría el derecho legal a no tener que alimentar al niño, esto es, a dejarle morir. (Rothbard $1995,150-151)$

Aquí se abren, como es obvio, varias posibilidades distópicas: madres que prefieren esperar al parto para abandonar a sus niños porque no 
tienen dinero para pagarse un aborto; niños abandonados merodeando por las calles que no están vigiladas o por las que se puede transitar sin pagar peajes; niños desnutridos o pandillas de niños que se unen para robar a algún transeúnte, y niños de esos grupos que son muertos por haber tenido la mala suerte de atacar a alguno que iba armado. Llegado a este punto, el lector podría quizás reconciliarse con la utopía anarcocapitalista si considera que en ella el trabajo infantil estaría permitido. ${ }^{28}$

Otro aspecto importante serían los cambios normativos que tendrían lugar en las utopías anarcocapitalistas. El derecho penal se reduciría drásticamente. ${ }^{29}$ No solamente porque se dejarían de perseguir los así llamados "delitos sin víctimas" (el consumo de drogas, algunas conductas autolesivas, etcétera) y se despenalizaría la producción y comercialización de drogas, sino porque, además, se despenalizarían el chantaje, las injurias y las calumnias. El primero de estos, sin ir más lejos, pasaría a ser considerado una forma legítima de intercambio. También se legalizaría la profesión del proxeneta, que pasaría a ser considerado un intermediario más. Se suprimiría el delito de la usura, pues no habría autoridad ni tampoco razón alguna para fijar el precio de los préstamos.

Desde el punto de vista de la ciudad, no habría lugares públicos (todas las calles serían privadas), de modo que podría ocurrir que hubiese gente que - al no aplicarse la estipulación de Locke/Nozick- no tuviera literalmente dónde estar o quedara encerrada por la propiedad de otros, que no le dejan pasar por la suya para ir a alguna otra parte. Es de suponer que habría gran segregación y que cada ciudad sería, en realidad, varias ciudades. Esa segregación, así como todo lo dicho hasta ahora, puede agravarse (por ejemplo, incluyendo la militarización de ciertas zonas de la ciudad, cordones de seguridad, toques de queda decretados por una junta de vecinos o un privado con un ejército particular, etcétera) si es que no se comparte el optimismo anarcocapitalista acerca de la eficacia y rapidez del capitalismo en la eliminación de la

${ }^{28}$ Comparar Block (2012, 367 y ss.).

${ }^{29}$ En realidad, desaparecerían todas las leyes positivas generales, pues la sociedad ideal de Rothbard se rige por los derechos naturales de los individuos (de los que se puede derivar un derecho penal muy general). Como no habría una autoridad centralizada, todos los vacíos o lagunas del derecho natural tendrían que ser llenados mediante acuerdos que regularan diversos aspectos de las relaciones de los individuos particulares. Uno puede imaginarse que cada individuo está sujeto a muy diversos contratos, con diferentes sujetos, etcétera. 
necesidad. Si ese supuesto es falso, es claro que la utopía anarcocapitalista será más parecida a la distopía de un estado de naturaleza hobbesiano.

\subsection{Hoppe: la utopía del neofeudalismo conservador}

Las utopías de Rothbard y Block todavía son formales, al menos en el sentido de que en ellas no se promueve explícitamente un particular estilo de vida. Y pese a que harían imposibles muchos estilos de vida, aún podría decirse que admiten varias utopías en su seno.

Ese no es el caso, sin embargo, de la utopía anarcocapitalista de Hoppe, que es una (micro)utopía que se levanta sobre una concepción sustantiva (bastante peculiar) de la vida buena, que es, además, derechamente hostil a todas las otras microutopías. Evidentemente, no es necesario que en las utopías del derecho privado las distintas comunidades mantengan relaciones fraternas. Basta con que reine la paz entre ellas, aunque sea, como dice Kukathas, por la indiferencia que se tienen. El caso de Hoppe es diferente, sin embargo, porque la suya es más bien una microutopía capitalista rodeada de comunidades disfuncionales, más o menos distópicas.

La concepción que lleva a este peculiar resultado se anuncia ya en el pasaje en que Hoppe divide la "raza humana" entre aquellos que son completamente incapaces "de comprender la mayor productividad de la división del trabajo y la propiedad privada", aquellos que "son capaces de comprender ese proceder, pero carecen de la fortaleza moral para actuar en consecuencia" $\mathrm{y}$, finalmente, aquellos que "actúan mal a sabiendas". El que pertenece a la primera categoría "no es, propiamente hablando, una persona, sino que moralmente es como un animal — de los inofensivos (que son domesticados y empleados como un bien de consumo o de producción, o utilizados como 'bienes libres') o de los salvajes y peligrosos (que hay que combatir como una plaga)" - . Los que se encuentran en el segundo caso "o son brutos inofensivos que viven al margen y apartados de la sociedad o criminales más o menos peligrosos". Las personas que se encuentran en la última categoría, "además de ser reprimidas o incluso reducidas físicamente, deben ser castigadas proporcionalmente a la gravedad de su crimen" (Hoppe 2004, 235-236).

La clasificación de Hoppe deja claro el problema: los que no comparten (“comprenden") los principios de la utopía anarcocapitalista o 
son incapaces de seguir sus reglas pueden ser tratados como animales, lo que no quiere decir sino que se les puede tratar como enemigos.

El hecho de que, además, Hoppe pueda señalar de antemano a los individuos que caerán en alguna de estas categorías resulta sorprendente, especialmente si se considera que él considera "esta teoría [es decir, el libertarianismo] como esencialmente irrefutable, como una verdad $a$ priori" (Hoppe 2015, 204). ¿Cómo a partir de ciertos principios pretendidamente a priori (propiedad sobre sí mismo, adquisición por prima occupatio, libertad contractual, etcétera) se llega a identificar a los indeseables, a los enemigos $\mathrm{y}$, en último término, a la escoria que será expulsada de la ciudad ideal de Hoppe?

Ello es posible por el modo en que Hoppe interpreta la información empírica a la cual se deben aplicar esos principios a priori. Su peculiar interpretación de la historia ofrece un ejemplo de ello. El decurso de la misma demostraría que "la teoría Whig de la historia, según la cual la humanidad avanza hacia niveles cada vez más altos de progreso, no es correcta" (Hoppe 2004, 116). La interrupción del progreso la ocasionaría el advenimiento de la democracia, que causaría una lenta pero inexorable decadencia social, política, económica y moral. Esta decadencia sería consecuencia de la colectivización de la propiedad que inevitablemente tiene lugar en las democracias: todos deciden por y sobre todo lo de todos los demás. Esa colectivización produciría una nueva "tragedia de los comunes", pues incentivaría el despilfarro, la irresponsabilidad y una visión infantil de la economía y la producción de bienes. Por su propio funcionamiento, la democracia aumentaría constantemente el rango de preferencia temporal de los individuos.

Otras observaciones o datos empíricos, refrendados, supuestamente, por las ciencias naturales o sociales, permitirían arribar a otras conclusiones igualmente importantes. Por ejemplo, que "el rico suele ser inteligente e industrioso, y el pobre, tonto, perezoso o las dos cosas" (Hoppe 2004, 149); que "la propiedad y las relaciones dominicales no existen al margen de las familias y las relaciones de parentesco" (2004, 270); que es la "típica familia blanca doméstica jerárquica de padre, madre, sus hijos comunes y futuros herederos y su conducta y estilo de vida 'burgués' — es decir, todo lo que la izquierda desprecia y difama" es el modelo de organización social económicamente más exitoso que el mundo haya visto nunca, "con la más grande acumulación de bienes 
de capital (riqueza) y los más altos estándares promedio de vida" (2015, 218)_; que el mestizaje de las clases superiores pertenecientes al estrato mercantil es beneficioso (una "mejora genética"), el de las demás clases, alentada por la integración forzosa de los Estados democráticos (es decir, la proscripción de la discriminación arbitraria), es perjudicial porque produce un "empobrecimiento genético" (genetic pauperization) (2007, 180); que "las habilidades físicas y mentales están desigualmente distribuidas", tanto entre los individuos como entre las diferentes sociedades del globo, y que las diferencias de rango, logro y autoridad entre esas personas y sociedades simplemente reflejan esas diferencias $(2015,227) .{ }^{30}$

Como fuere, lo importante es que Hoppe cree estar en condiciones de poder identificar un conjunto de personas que, por diferentes razones, deben ser expulsadas de la utopía anarcocapitalista que él describe. ¿Quiénes son, concretamente estos individuos?

Aquellos que tienen un alto rango de preferencia temporal y que, en consecuencia, tienden al despilfarro, el parasitismo, la irresponsabilidad, etcétera, que deben ser objeto de la más decidida discriminación:

Los libertarios deben distinguirse de los demás practicando y defendiendo las formas más radicales de intolerancia y discriminación contra los igualitaristas, demócratas, socialistas, comunistas, multiculturalistas y ecologistas, contra las costumbres pervertidas, los comportamientos antisociales, la incompetencia, la indecencia, la vulgaridad y la obscenidad. (Hoppe 2004, 288)

En otro pasaje se refiere a la posibilidad de expulsar a los indeseables:

Un orden social libertario no puede tolerar ni a los demócratas ni a los comunistas. Será necesario apartarlos físicamente de los

${ }^{30}$ Este pasaje del texto de Hoppe es vago, pues puede entenderse de varios modos. Que existen diferencias de talentos, habilidades, etcétera, entre individuos es indiscutible; que las estratificaciones, logros, jerarquías, etcétera, de una sociedad reflejen sin más esas diferencias naturales no lo es. Que, por otra parte, los talentos, habilidades, etcétera, estén repartidos desigualmente entre las sociedades (o entre las "razas", pues Hoppe cita más de una vez con aprobación a J. Phillippe Rushton, quien sostiene que esas diferencias se explican por distintas estrategias evolutivas) es derechamente falso. En cualquier caso, Hoppe no sólo parece empeñado en naturalizar esas diferencias, sino que además en justificarlas moralmente. 
demás y extrañarlos. Del mismo modo, en un pacto instituido con la finalidad de proteger a la familia, no puede tolerarse a quienes promueven formas de vida alternativas, no basadas en la familia ni en el parentesco, incompatibles con aquella meta. También estas formas de vida alternativas - hedonismo individualista, parasitismo social, culto al medio ambiente, homosexualidad o comunismo - tendrán que ser erradicadas de la sociedad si se quiere mantener un orden libertario. (Hoppe 2004, 287)

Puesto que toda la tierra sería privada, los dueños de los territorios en que se asientan las ciudades libertarias (grandes propietarios, que harían las veces de autoridad política) podrían legítimamente expulsar de sus territorios a todos aquellos que no cumplieran el contrato de convivencia. Después de todo, dice Hoppe, "toda propiedad privada presupone una discriminación, pues si tal o cual cosa me pertenece, ello quiere decir que a usted no le pertenece y que yo estoy facultado para excluirle a usted de ella" (Hoppe 2004, 276).

Toda esta construcción rebosa arbitrariedad e ingenuidad. A Hoppe le preocupan las condiciones culturales que permiten la conservación del capitalismo y achaca, íntegramente, la presunta destrucción de esas condiciones (es decir, de la sociedad blanca, cristiana y heterosexual) a la expansión del Estado que ha tenido lugar a contar del siglo XX. Sin embargo, no contempla la posibilidad de que sea la misma expansión capitalista la que destruya esos modos de vida que él tanto ansía preservar. Una sociedad uniforme como la que él describe (y que seguramente tampoco existió nunca) no resulta posible más que bajo un fuerte disciplinamiento y control social. Gran parte de ese control sólo puede ser eficaz, en último término, si es coactivo.

Lo cierto es que el desiderátum liberal es incompatible con el tipo de sociedad jerarquizada, conservadora y segregada que promueve Hoppe. Piénsese, por ejemplo, en el caso de las mujeres. ¿Cuál es la probabilidad de que, teniendo la posibilidad de trabajar, la generalidad de ellas se someta, libre y voluntariamente, al señorío de un hombre, para conformar la familia tradicional por la que aboga Hoppe? Sobre todo, ¿cuál es esa probabilidad en una sociedad libertaria en la que, es de suponer, se ha dicho a las mujeres que, como los hombres, son dueñas de sus propios cuerpos? Si, como creía Fourier, el grado de libertad de que goza la mujer determina la estructura social en su conjunto (Fou- 
rier 1974, 167), ¿cómo podría preservar el libertarismo el modelo de sociedad que anhela Hoppe? Schumpeter, por su parte, muchísimo más perspicaz que Hoppe, se refería al feminismo como un fenómeno "esencialmente capitalista" (Schumpeter 2015, 241).

Lo mismo vale para los demás aspectos de la vida social, pues, si se concede a los individuos libertad, rápidamente aflorará la diversidad y proliferarán "los modos de vida alternativos", que tan deplorables le resultan a Hoppe.

Pero, por lo demás, ¿qué razones podría esgrimir una filosofía no perfeccionista como la de Hoppe para que individuos libres eligieran el modo de vida que él defiende? ¿Qué razón podría esgrimir Hoppe para que los blancos heterosexuales vayan a vivir a su muy aburrida (y seguramente altamente reglada) ciudad ideal, fuera de la necesidad de preservar el capitalismo? Sin perjuicio del absurdo de creer que el capitalismo necesita defensores (la quijotada tonta de Hoppe sería desopilante si no tuviera tantos parecidos con el fascismo), ¿puede ser la conservación del capitalismo el fin de la vida de alguien?

\section{CONCLUSIÓN}

Las utopías son metáforas de las teorías políticas. Como tales, nos permiten apreciar las fortalezas y debilidades de las ideas en que se inspiran y del modelo político que proyectan. Las teorías del derecho privado son una utopía de la libertad individual, en la que la vida de cada individuo no es más que el resultado de sus elecciones y preferencias (y su buena o mala suerte). Para dar curso a esa aspiración, estas utopías abogan por un mundo sin derecho público, esto es, un mundo en el que el concepto de ciudadanía y de derechos políticos han desaparecido. Por eso, a medida que se extreman las premisas o supuestos de las utopías del derecho privado, se reduce progresivamente el papel y la necesidad de algunos de los conceptos políticos de la Ilustración, como el de la igualdad ante la ley, entendida como la supresión de estatutos personales y la aplicación del mismo conjunto de leyes para todos.

Nozick y Kukathas esperan que, fuera de la obligación mínima de no agredir a otros, las preferencias de los individuos determinen el conjunto de derechos y obligaciones que tiene cada cual. Puesto que habría libertad de elección, ese conjunto de derechos y obligaciones se 
diversificarían en diferentes lotes, del mismo modo que se diversificaría la oferta de mercancías en un mercado libre.

Llegado a este punto, uno podría recordar el reproche de Aristóteles a Platón y decir que los autores utópicos esperan que las cosas evolucionen en una dirección (por ejemplo, que, una vez abolida la familia, todos traten a todos los niños que encuentren como sus hijos), cuando en realidad probablemente lo harían en otra (los niños serían abandonados).

¿Cómo se aplicaría el reproche de Aristóteles a estas utopías del derecho privado? Los libertarios y anarcocapitalistas esperan que sus utopías reflejen un mundo en el que la libertad de todos y cada uno de los individuos tiene sus máximas posibilidades de expresión. A menos que haya cometido un delito o dañado a otro, nadie tiene más obligaciones que las que expresamente contrae.

Sin embargo, dadas las premisas de las utopías del derecho privado - particularmente, i) su tratamiento deficiente o, en sus versiones más extremas, la ligereza con que se desechan los casos de necesidad, y ii) su identificación de la libertad con la ausencia de coacción-, lo más probable es que, en lugar de maximizar las posibilidades de realización de todos sus habitantes, las utopías libertarias y anarcocapitalistas fueran espacios en los que algunos contaran con grandes oportunidades para la realización de sus libertades y adquirieran, además, muchos y tal vez muy extensos derechos sobre otros, que por su parte vieran comprometida su libertad por esas enajenaciones o, peor aún, se vieran reducidos a luchar contra la necesidad.

Dicho de otro modo, las condiciones materiales para el ejercicio de la libertad, sumadas a la posibilidad de alienar todos o casi todos los derechos que se tienen, producirían, no que el conjunto de derechos y obligaciones de que son titulares los individuos reflejara sus preferencias, sino que, más bien, reflejara aquello que simplemente pudieron conseguir. Habría entonces un sistema parecido al de castas, pues sucedería con los derechos individuales lo mismo que con los productos de un mercado: se diversificarían la calidad y extensión de los paquetes de derechos y obligaciones, no sólo según las preferencias de los individuos, sino que también según lo que están en condiciones de adquirir.

Este resultado demostraría que, en términos kantianos, las utopías del derecho privado (al menos en sus versiones más extremas) no for- 
mulan un sistema de libertades que puedan coexistir "según una ley universal". Al admitir la posibilidad de enajenar la propia personalidad o desestimar los casos de necesidad, las utopías del derecho privado ponen condiciones que son inconsistentes con la realización de la libertad de todos los agentes morales. Esta coletilla que Kant incluye en el principio universal del derecho (y que tal vez podemos llamar la "estipulación de Kant" ${ }^{31}$ ), que exige que las libertades de los individuos puedan coexistir "según leyes universales", no es un mero pleonasmo. $\mathrm{Su}$ olvido explica que las utopías del derecho privado sean no sólo un esfuerzo de reducir toda la teoría de la justicia a la justicia correctiva, sino que además sean la distopía jurídica que resulta del intento —que Wittgenstein desaprobaría - de explicar la justicia y discurrir acerca de la ciudad ideal a partir de un lenguaje puramente privado.

\section{REFERENCIAS}

Aristóteles. 2005. Política, traducción de Julián Marías y María Araujo. Madrid: Centro de Estudios Políticos y Constitucionales.

Block, Walter. 2012. Defendiendo lo indefendible, traducción de Diego González Calles. Madrid: Unión Editorial.

Boettke, Peter J. \& Rosolino A. Candela. 2018. "Liberal Libertarianism". En The Routledge Handbook of Libertarianism, editado por Jason Brennan, Bas van der Vossen y David Schmidtz. New York \& London: Taylor \& Francis.

Estlund, David. 2014. "Utopophobia”. Philosophy \& Public Affairs 42 (2): 113-134.

Feser, Edward. 2005. "There Is no Such Thing as an Unjust Initial Acquisition”. En Natural Rights Liberalism from Locke to Nozick, editado por Elle Franken Paul, Fred D. Miller Jr. y Paul Jeffrey, 56-80. Cambridge: Cambridge University Press.

Fourier, Charles. 1974. Teoría de los cuatro movimientos y de los destinos generales, traducción de Francisco Monge. Barcelona: Barral.

Freeman, Samuel. 2018. "Liberal and Iliberal Libertarianism". En The Routledge Handbook of Libertarianism, editado por Jason Brennan, Bas van der Vossen y David Schmidtz, 128-144. Nueva York \& London: Taylor \& Francis.

- 2018. Liberalism and Distributive Justice. Nueva York: Oxford University Press.

Fukuyama, Francis. 2018. Identity. The Demand for Dignity and the Politics of Resentment. Nueva York: Farrar, Straus and Giroux.

${ }^{31}$ Ver Kant, $A k$ VI, 230. 
Ganshof, François L. 2019. El feudalismo, traducción de Feliu Formosa. Barcelona: Ariel.

Hawley, George. 2018. The Alt-Right. What Everyone Needs to Know. Nueva York: Oxford University Press.

Hayek, Friedrich A. 2006. Derecho, legislación y libertad. Una nueva formulación de los principios liberales de la justicia y de la economía politica. Madrid: Unión Editorial.

- 2012. Estudios de filosofía, política y economía. Madrid: Unión Editorial.

Hidalgo, Javier. 2017. "The Libertarian Case for Open Borders". En The Routledge Handbook of Libertarianism, editado por Jason Brennan,Bas van der Vossen \& David Schmidtz. New York: Taylor \& Francis.

Hoppe, Hans-Hermann. 1987. Eigentum, Anarchie und Staat. Studien zur Theorie des Kapitalismus. Opladen: Westdeutscher Verlag.

- 2004. Monarquía, democracia y orden natural: una visión austríaca de la era americana, traducción de Jerónimo Molina. Madrid: Ediciones Gondo.

- 2007. Democracy. The God That Failed. The Economics and Politics of Monarchy, Democracy, and Natural Order. New Brunswick \& London: Transaction Publishers.

_. 2015. “A Realistic Libertarianism”. Procesos de mercado. Revista europea de Economía Política XII (1): 203-229.

Hume, David. 2006. "Del contrato original". En Ensayos politicos, traducción de César Armando Gómez, 97-115. Madrid: Tecnos.

Kant, Immanuel. 1910-1917; 1923-1972. Kants Gesammelte Schriften herausgegeben von der Königlich Preussischen Akademie der Wissenschaften. Volúmenes I-XXVIII. Berlin, Leipzig: Georg Reimer; Walter de Gruyter.

Kukathas, Chandran. 2003. The Liberal Archipielago. A Theory of Diversity and Freedom. New York: Oxford University Press.

_. 2009. "Two Constructions of Libertarianism". Libertarian Papers 1: 1-14. - 2011. "E pluribus plurum, or How to Fail to Get to Utopia in Spite of Really Trying". En The Cambridge Companion to Nozick's Anarchy, State, and Utopia, editado por Ralf M. Baader y John Meadowcroft, 289-302. Nueva York: Cambridge University Press.

Locke, John. 2002. Segundo tratado sobre el gobierno civil. Un ensayo acerca del verdadero origen, alcance y fin del gobierno civil, traducción de Carlos Mellizo. Madrid: Alianza.

Marx, Karl. 2012. El capital, traducción de Pedro Scaron. Vol. I. Buenos Aires: Siglo Veintiuno Editores.

Misseri, Lucas. 2011. "Microutopismo y fragmentación social: Nozick, Iraburu y Kumar". En-claves del Pensamiento 5 (10): 75-88.

Narveson, Jan. 2001. The Libertarian Idea. Canada: Broadview Press.

Nozick, Robert. 1988. Anarquía, Estado y utopía, traducción de Rolando Tamayo. México: Fondo de Cultura Económica. 
. 1992. Meditaciones sobre la vida, traducción de Carlos Gardini. Barcelona: Gedisa.

—. 1999. Puzzles socráticos, traducción de Agustín Coletes. Madrid: Cátedra.

Okin, Susan Moller. 1989. Justice, Gender, and the Family. Nueva York: Basic Books.

Otsuka, Michael. 2003. Libertarianism without Inequality. Nueva York: Oxford University Press.

Popper, Karl R. 1991. Conjeturas y refutaciones, traducción de Néstor Míguez. Barcelona: Paidós.

_ 2017. La sociedad abierta y sus enemigos, traducción de Eduardo Leodel. Barcelona: Paidós.

Roark, Eric. 2013. Removing the Commons. Plymouth: Lexington Books.

Rothbard, Murray N. 1977. Power and Market: Government and the Economy. Kansas: Sheed Andrews and McMeel.

-1995. La ética de la libertad, traducción de Marciano Villanueva Salas. Madrid: Unión Editorial.

- 1998. The Ethics of Liberty. New York \& London: New York University Press.

Schumpeter, Joseph A. 2015. Capitalismo, socialismo y democracia, traducción de José Díaz García y Alejandro Limeres. Vol. I. Barcelona: Página Indómita.

Schwember, Felipe. 2018. “Liberalismo y derechos sociales? Las vías libertarias hacia el Estado más que mínimo”. HYBRIS. Revista de Filosofía 9 (n. ${ }^{\circ}$ especial: Debates contemporáneos sobre justicia social): 149-183.

_ 2019. "The Twisted Path to Dystopia: The Libertarian Utopias of Private Law", en Disciplines of the City: New Forms of Governance in Today's Postmetropolises, editado por Julia Urabayen y Jorge León Casero, 107-133. Nueva York: Nova Science Publishers.

Schwember, Felipe \& Julia Urabayen. 2018. "At the Margins of Ideal Cities: The Dystopian Drift of Modern Utopias". SAGE Open 8 (4).

Vallentyne, Peter \& Hillel Steiner. 2000. Left-Libertarianism and Its Critics: The Contemporary Debate. Nueva York: Palgrave Publishers.

- 2000. The Origins of Left-Libertarianism. An Anthology of Historical Writings. Nueva York: Palgrave Publishers.

Van Parijs, Philippe. 1996. Libertad real para todos. Qué puede justificar el capitalismo (si hay algo que pueda hacerlo). Barcelona: Paidós.

Widerquist, Karl. 2010. "Lockean Theories of Property: Justifications for Unilateral Appropriation". Public Reason 2 (1): 3-26. EP 